\title{
EDUCACIÓN CONTINUADA EN ORTOPEDIA Y TRAUMATOLOGÍA hOSPITAL DE SAN JOSÉ DE BOGOTÁ
}

Fernando A. Carreño Mesa MD*

La conformación del Servicio de Ortopedia y Traumatología en el Hospital de San José de Bogotá se realizó en 1961 cuando el doctor Jorge Ruiz Ruiz vinculó especialistas con excelente formación académica a nivel nacional e internacional, para el desempeño de la práctica profesional.

El interés por la excelencia y el conocimiento académico adquirido en nuestro servicio, permitió la creación en 1968 del programa de entrenamiento formal en ortopedia y traumatología. Con el surgimiento de las subespecialidades ortopédicas, en 1983 ingresa el doctor Edgar Muñoz Vargas, aportando sus conocimientos y el entrenamiento recibido en Estados Unidos para el desarrollo de la cirugía reconstructiva y artroscópica de la rodilla, convirtiéndose en pionero de estas nuevas técnicas en nuestro país. Su experiencia le ha permitido desempeñarse como conferencista nacional e internacional, jefe del departamento médico del Club Deportivo “Los Millonarios" desde 1987 hasta la fecha y médico traumatólogo de la selección colombiana de mayores de fútbol en el año 2000.

Fue Presidente de la Sociedad Colombiana de Ortopedia y Traumatología (1997-1998), jefe del Servicio de Ortopedia y Traumatología, y de la Unidad Quirúrgica del Hospital de San José de Bogotá.

La continua dedicación en la formación académica y el compromiso que tienen los Servicios de Ortopedia y

* Ortopedista y traumatólogo. Instructor asistente, Fundación Universitaria de Ciencias de la Salud, Coordinador General del Curso de Artroscopia, Hospital de San José, marzo de 2012.

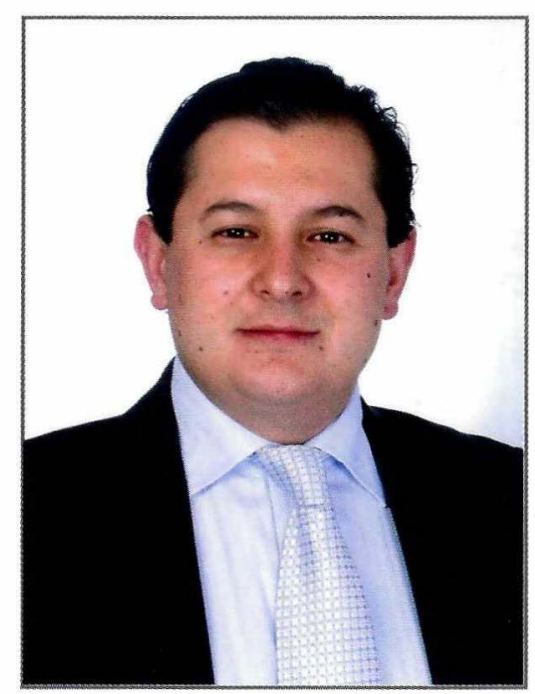

Traumatología y de Artroscopia, le permitió al doctor Muñoz realizar la creación del programa de posgrado de la subespecialidad para el entrenamiento en rodilla y artroscopia desde 2007. El grupo de instructores de rodilla del Hospital de San José de Bogotá está conformado por egresados de la subespecialidad, como son los doctores Carlos E. Pardo actual Jefe del Servicio de Ortopedia, Gustavo A. Rincón y Carlos E. López.

Las diferentes técnicas endoscópicas han evolucionado en otras articulaciones del cuerpo humano, lo cual ha permitido resultados satisfactorios predecibles con la ventaja de ser procedimientos mínimamente invasivos. En la actualidad el Hospital de San José de Bogotá cuenta con excelentes especialistas en diversas áreas como la clínica de rodilla, clínica de hombro y codo conformada por los doctores Luis A. Pinzón y. Fernan- 
do A. Carreño, clínica de artroscopia de cadera con el doctor Juan M. Nossa y clínica de mano el doctor Jaime Forígua.

El Servicio de Ortopedia y Traumatología del Hospital de San José de Bogotá y la Fundación Universitaria de Ciencias de la Salud tienen como objetivo común brindar educación continuada para la ortopedia nacional, por esta razón se realizó en el año 2010 el III Curso Colombiano de Medicina del Fútbol y Trauma Deportivo y en marzo de este año el I Curso de Revisión de Remplazos Articulares en Hombro, Rodilla y Cadera. Este escenario académico ha logrado ser reconocido a nivel nacional como uno de los mejores eventos en ortopedia, apoyado por la Sociedad Colombiana de
Cirugía Ortopédica y de Traumatología (SCCOT), gracias al cumplimiento de los objetivos planeados basados en la calidad de las conferencias y discusiones académicas, los invitados nacionales e internacionales y un programa acorde con las necesidades actuales de la especialidad.

Es para nosotros un placer en esta oportunidad invitarlos a participar en el IV Curso Colombiano de Medicina del Fútbol y Trauma Deportivo - Actualización en Trauma Deportivo Pediátrico que se realiza el 9 y 10 de marzo de 2012 en el Hotel Dann Carlton de Bogotá. Incluye el I Seminario de Trauma Deportivo del Hospital de San José de Bogotá, "Enfoque Global del Niño Deportista". 